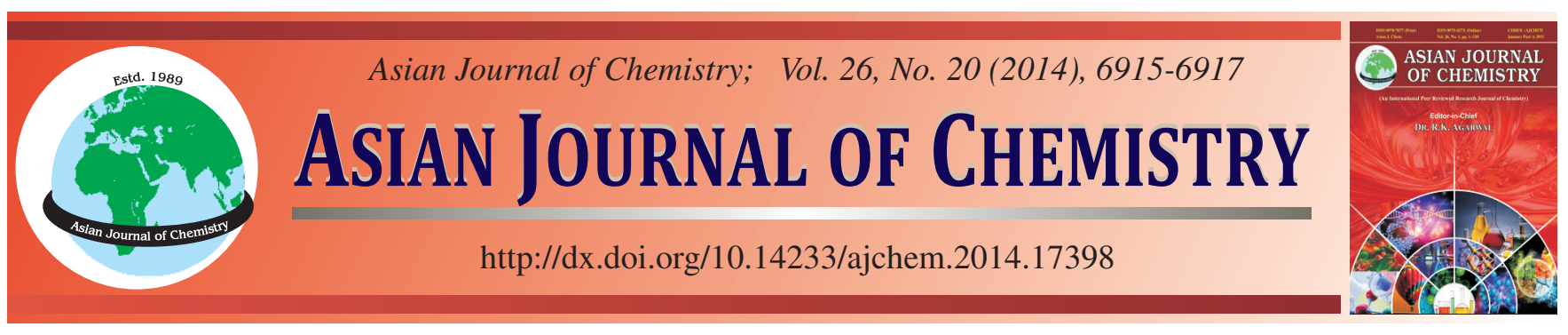

\title{
Synthesis and Characterization of Bromo-Substituted Salamo-Type Bisoxime Compounds Series
}

\author{
Li Xu, Na Li, Yang Zhang, Na Wen, Li-Chun Zhu and Xiu-Yan Dong*
}

School of Chemical and Biological Engineering, Lanzhou Jiaotong University, Lanzhou 730070, P.R. China

*Corresponding author: E-mail: dxy568@163.com

Received: 14 February 2014;

Accepted: 5 May 2014;

Published online: 25 September 2014;

AJC-16038

Four novel bromo-substituted Salamo-type bisoxime compounds $\mathbf{H}_{2} \mathbf{L}^{1}-\mathbf{H}_{2} \mathbf{L}^{4}$ have been synthesized from 5-bromo-2-hydroxybenzaldehyde and 1,3-bis(aminooxy)propane, 1,4-bis(aminooxy)butane, 1,5-bis(aminooxy)pentane or 1,6-bis(aminooxy)henane in hot ethanolic medium, respectively and characterized by elemental analyses, IR, UV-visible spectra and ${ }^{1} \mathrm{H}$ NMR spectroscopy.

Keywords: Salamo-type compound, Synthesis, Characterization.

\section{INTRODUCTION}

Salamo-type bisoxime compounds have long been used as organic chelating ligands in the synthesis of transition metal complexes, because this compound could be prepared easily from salicylaldehyde and various amines ${ }^{1-4}$. In recent years, these complexes have been found to possess multifarious interesting property. Thus, we have recently studied three novel Salamo-type bisoxime chelating compounds on the basis of $O$-alkyloxime moiety [-CH=N-O- $\left.\left(\mathrm{CH}_{2}\right)_{\mathrm{n}}-\mathrm{O}-\mathrm{N}=\mathrm{CH}-\right]$ group $^{5-7}$. Herein, we report the synthesis and characterization of four Salamo-type bisoximes compounds, 4,4'-bibromo-2,2'[(propylene-1,3-diyldioxy)bis(nitrilomethylidyne)]-diphenol, 4,4'-bibromo-2,2'-[(butylene-1,4-diyldioxy) bis-(nitrilomethylidyne)]diphenol, 4,4'-bibromo-2,2'-[(propane-1,5diyldioxy)bis(nitrilomethylidyne)]diphenol and 4,4'-dibromo2,2'-[(hexane-1,6-diyldioxy)bis(nitrilomethylidyne)]diphenol.

\section{EXPERIMENTAL}

5-Bromo-2-hydroxy-benzaldehyde ( $\geq 98 \%$ ), 1,3-dibromopropane, 1,4-dibromobutane, 1,5-dibromopentane and 1,6dibromohexane were purchased from Alfa Aesar and used without further purification. The other reagents and solvents were analytical grade reagents from Tianjin Chemical Reagent Factory. The others are the same as literature ${ }^{8-10}$.

General procedure: Synthetic route to Salamo-type bisoxime compounds $\mathbf{H}_{2} \mathbf{L}^{1}-\mathbf{H}_{2} \mathbf{L}^{\mathbf{4}}$ are shown in Fig. 1. 1,3-bis(aminooxy)propane, 1,4-bis(aminooxy)butane, 1,5-bis(aminooxy)pentane and 1,6-bis(aminooxy)henane were synthesized according to an analogous method reported earlier ${ }^{8-10}$.

Preparation of 4,4'-dibromo-2,2' [(propylene-1,3diyldioxy)bis(nitrilomethylidyne)]diphenol $\left(\mathbf{H}_{2} \mathbf{L}^{1}\right)$ : To an ethanolic solution $(10 \mathrm{~mL})$ of 5-bromo-2-hydroxybenzaldehyde (603.1 mg, $3 \mathrm{mmol}$ ) was added an ethanolic solution (10 mL) of 1,3-bis(aminooxy)propane (159.2 mg, $1.50 \mathrm{mmol}$ ). After the solution had been stirred at $55^{\circ} \mathrm{C}$ for $2 \mathrm{~h}$, the mixture was filtered, washed successively with ethanol and $n$-hexane, respectively. The product was dried under reduced pressure and purified with recrystallization from ethanol to yield white crystalline solid $\mathbf{H}_{2} \mathbf{L}^{1}$.

Preparation of 4,4'-dibromo-2,2'-[(butylene-1,4diyldioxy)bis(nitrilomethylidyne)]diphenol $\left(\mathbf{H}_{2} \mathbf{L}^{2}\right)$ : To a hot ethanol solution $(10 \mathrm{~mL})$ of 5-bromo-2-hydroxybenzaldehyde $(603.1 \mathrm{mg}, 3 \mathrm{mmol})$ was added a hot ethanolic solution $(5 \mathrm{~mL})$ of 1,5-bis(aminooxy)pentane (201.6 mg, $1.50 \mathrm{mmol})$. After

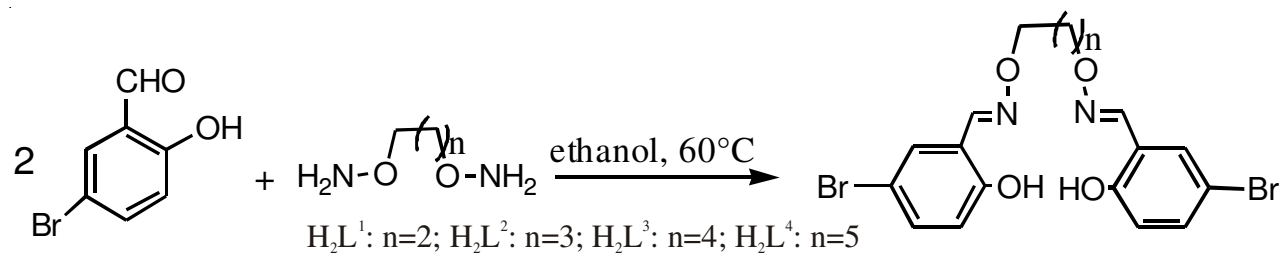

Fig. 1. Synthetic route to salamo-type bisoxime compounds $\mathrm{H}_{2} \mathrm{~L}^{1}-\mathrm{H}_{2} \mathrm{~L}^{4}$ 
the solution had been stirred at $55^{\circ} \mathrm{C}$ for $3 \mathrm{~h}$, then cooled to room temperature. The white precipitate was formed, filtered and washed successively with ethanol and $n$-hexane, respectively. The product was purified with recrystallization from ethanol $/ n$-hexane (1/4) and dried under vacuum to obtain white needle-like compound $\mathbf{H}_{2} \mathbf{L}^{2}$.

Preparation of 4,4'-dibromo-2,2'-[(propane-1,5diyldioxy)bis(nitrilome-thylidyne)]diphenol $\left(\mathbf{H}_{2} \mathbf{L}^{3}\right)$ : To a hot ethanolic solution $(15 \mathrm{~mL})$ of 5-bromo-2-hydroxy-benzaldehyde (201.3 mg, $1 \mathrm{mmol}$ ) was added a hot ethanolic solution (10 mL) of 1,5-bis(aminooxy)pentane (67.1 mg, $0.50 \mathrm{mmol}$ ). After the solution had been stirred at $60^{\circ} \mathrm{C}$ for $6 \mathrm{~h}$, then cooled to room temperature. The white precipitate which was filtered and washed successively with ethanol and $n$-hexane, respectively. The product was purified with recrystallization from ethanol $/ n$-hexane (1/4) and dried under vacuum to obtain white cotton-like compound $\mathbf{H}_{2} \mathbf{L}^{3}$.

Preparation of 4,4'-bibromo-2,2'-[(hexane-1,6diyldioxy)bis(nitrilomethylidyne) ]diphenol $\left(\mathbf{H}_{2} \mathbf{L}^{4}\right)$ : To a hot ethanolic solution $(15 \mathrm{~mL})$ of 5-bromo-2-hydroxy-benzaldehyde (201.3 mg, $1 \mathrm{mmol}$ ) was added a hot ethanolic solution (10 mL) of 1,6-bis(aminooxy)henane (74.1 mg, $0.50 \mathrm{mmol})$. After the solution had been stirred at $60^{\circ} \mathrm{C}$ for $6 \mathrm{~h}$, then cooled to room temperature. The white precipitate which was filtered and washed successively with ethanol and $n$-hexane, respectively. The product was purified with recrystallization from ethanol $/ n$-hexane (1/4) and dried under vacuum to obtain white cotton-like compound $\mathbf{H}_{2} \mathbf{L}^{4}$.

\section{RESULTS AND DISCUSSION}

Four Salamo-type bisoxime compounds $\mathbf{H}_{2} \mathbf{L}^{1}-\mathbf{H}_{2} \mathbf{L}^{4}$ have been synthesized with good yields and the composition are confirmed by elemental analyses, IR, UV-visible spectra and ${ }^{1} \mathrm{H}$ NMR spectroscopy.

Physico-chemical properties: The colour, yields, melting points and elemental analytical results of the synthesized Salamo-type bisoxime compounds $\mathbf{H}_{2} \mathbf{L}^{1}-\mathbf{H}_{2} \mathbf{L}^{4}$ are presented in Table-1. Their compositions agree with the proposed molecular formula. All the compounds are stable in air and soluble in chloroform, dichloromethane, tetrahydrofuran, benzene, acetone, DMF and DMSO, insoluble in $n$-hexane, ether and water. In addition, $\mathbf{H}_{2} \mathbf{L}^{1}$ and $\mathbf{H}_{2} \mathbf{L}^{2}$ are soluble in hot methanol, ethanol and acetonitrile, but $\mathbf{H}_{2} \mathbf{L}^{3}$ and $\mathbf{H}_{2} \mathbf{L}^{4}$ are insoluble in hot methanol, ethanol and acetonitrile.

IR spectra: The most important IR spectra data for $\mathbf{H}_{2} \mathbf{L}^{\mathbf{1}}$ $\mathbf{H}_{2} \mathbf{L}^{4}$ are given in Table-2. In the IR spectra of the compounds $\mathbf{H}_{2} \mathbf{L}^{1}-\mathbf{H}_{2} \mathbf{L}^{4}$, the characteristic $\mathrm{C}=\mathrm{N}$ stretching bands of the compound $\mathbf{H}_{2} \mathbf{L}^{\mathbf{1}}-\mathbf{H}_{2} \mathbf{L}^{4}$ appear at $1614-1611 \mathrm{~cm}^{-1}$, respectively ${ }^{11}$. The Ar-O stretching bands occur at $1265-1255 \mathrm{~cm}^{-1}$ as reported for similar bisoxime compounds ${ }^{12}$. Meanwhile, the $\mathrm{O}-\mathrm{H}$ stretching bands of phenolic alcohol in the title compounds $\mathbf{H}_{2} \mathbf{L}^{1}-\mathbf{H}_{2} \mathbf{L}^{4}$ appear at $3441-3424 \mathrm{~cm}^{-1}$ region, but this frequency is generally displaced to ca. $3424 \mathrm{~cm}^{-1}$ because of the internal hydrogen bond $\mathrm{OH} \cdots \mathrm{N}=\mathrm{C}^{10}$. In addition, in the $1481-1479 \mathrm{~cm}^{-1}$ region, the observed bands were attributed to aromatic $\mathrm{C}=\mathrm{C}$ vibrations.

UV-visible and ${ }^{1} \mathbf{H}$ NMR spectra: The UV-visible spectra of the compounds $\mathbf{H}_{2} \mathbf{L}^{1}-\mathbf{H}_{2} \mathbf{L}^{4}$ in $5 \times 10^{-5}$ mol L $\mathrm{L}^{-1}$ dichloromethane solution are presented in Table-3. The compounds $\mathbf{H}_{2} \mathbf{L}^{\mathbf{1}}$ $\mathbf{H}_{2} \mathbf{L}^{4}$ exhibit two intense peaks at around 277 and $315 \mathrm{~nm}$. The former absorption peaks at about $277 \mathrm{~nm}$ can be assigned to the $\pi-\pi^{*}$ transition of the benzene rings, while the latters can be attributed to the intra-ligand $\pi-\pi^{*}$ transition of the $\mathrm{C}=\mathrm{N}$ bonds ${ }^{13}$. It is of note that there was no absorption around $400 \mathrm{~nm}$, which is seen in the corresponding Salen derivatives. The absorption is ascribed to the quinoid form of $\mathrm{H}_{2}$ salen $^{14,15}$.

The ${ }^{1} \mathrm{H}$ NMR spectra of the title compounds $\mathbf{H}_{2} \mathbf{L}^{\mathbf{1}}-\mathbf{H}_{2} \mathbf{L}^{\mathbf{4}}$ in DMSO- $d_{6}$ are shown in Table-3. The ${ }^{1} \mathrm{H}$ NMR spectra showed a singlet at about $8.25-8.45 \mathrm{ppm}$ indicating the existence of oxime bonds ${ }^{14}$.

\section{Conclusion}

Four novel Salamo-type compounds $\mathbf{H}_{2} \mathbf{L}^{1}-\mathbf{H}_{2} \mathbf{L}^{4}$ that have two oxime bonds instead of imine bonds have been designed and synthesized by the reaction of 2 equivalents of 5-bromo2-hydroxy-benzaldehyde with 1,3-bis(aminooxy)propane, 1,4bis(aminooxy)butane, 1,5-bis(aminooxy)pentane or 1,6bis(aminooxy)henane in hot ethanol medium, respectively. And the structures of the title compounds $\mathbf{H}_{2} \mathbf{L}^{\mathbf{1}}-\mathbf{H}_{2} \mathbf{L}^{4}$ have been analyzed by elemental analysis, IR, UV-visible spectra and ${ }^{1}$ H NMR spectroscopy. The Salamo-type compounds may be promising units for the construction of supramolecular metal complexes.

TABLE-1

COLOUR, YIELDS, MELTING POINTS AND ANALYTICAL

DATA OF SYNTHESIZED SALAMO-TYPE BISOXIME COMPOUNDS $\mathbf{H}_{2} \mathbf{L}^{1}-\mathbf{H}_{2} \mathbf{L}^{\mathbf{4}}$

\begin{tabular}{cccccccc}
\hline \multirow{2}{*}{ Compound } & \multirow{2}{*}{ Colour } & \multirow{2}{*}{ m.p. $\left({ }^{\circ} \mathrm{C}\right)$} & \multirow{2}{*}{ Yield $(\%)$} & \multirow{2}{*}{ m.f. (m.w.) } & \multicolumn{3}{c}{ Elemental analysis (\%): Found (Calcd.) } \\
\cline { 6 - 8 } & & & & $\mathrm{C}$ & \multicolumn{2}{c}{$\mathrm{H}$} & $\mathrm{N}$ \\
\hline $\mathbf{H}_{\mathbf{2}} \mathbf{L}^{\mathbf{1}}$ & White & $163-164$ & 59.0 & $\mathrm{C}_{17} \mathrm{H}_{16} \mathrm{~N}_{2} \mathrm{O}_{4} \mathrm{Br}_{2}(472.13)$ & $43.85(43.25)$ & $3.44(3.42)$ & $5.69(5.93)$ \\
$\mathbf{H}_{2} \mathbf{L}^{2}$ & White & $143-144$ & 60.1 & $\mathrm{C}_{18} \mathrm{H}_{18} \mathrm{~N}_{2} \mathrm{O}_{4} \mathrm{Br}_{2}(486.15)$ & $44.56(44.47)$ & $3.96(3.73)$ & $5.68(5.76)$ \\
$\mathbf{H}_{2} \mathbf{L}^{3}$ & White & $121-122$ & 76.3 & $\mathrm{C}_{19} \mathrm{H}_{20} \mathrm{~N}_{2} \mathrm{O}_{4} \mathrm{Br}_{2}(500.18)$ & $45.62(45.31)$ & $4.03(4.10)$ & $5.60(5.62)$ \\
$\mathbf{H}_{\mathbf{2}} \mathbf{L}^{4}$ & White & $134-135$ & 63.2 & $\mathrm{C}_{20} \mathrm{H}_{22} \mathrm{~N}_{2} \mathrm{O}_{4} \mathrm{Br}_{2}(514.21)$ & $46.72(46.65)$ & $4.31(4.36)$ & $5.45(5.51)$ \\
\hline
\end{tabular}

TABLE-2

\begin{tabular}{ccccccc}
\multicolumn{7}{c}{ TABLE-2 } \\
\multicolumn{7}{c}{ KEY IR BANDS FOR THE SALAMO-TYPE BISOXIME COMPOUNDS $\mathbf{H}_{2} \mathbf{L}^{\mathbf{1}}-\mathbf{H}_{2} \mathbf{L}^{\mathbf{4}}\left(\mathrm{cm}^{-1}\right)$} \\
\hline Compound & $v(\mathrm{O}-\mathrm{H})$ & $v\left(\mathrm{CH}_{\text {arom }}\right)$ & $v\left(\mathrm{CH}_{2}\right)$ & $v(\mathbf{C}=\mathrm{N})$ & $v(\mathrm{C}-\mathrm{C})_{\text {benzene ring }}$ & $v($ Ar-O) \\
\hline $\mathbf{H}_{2} \mathbf{L}^{\mathbf{1}}$ & 3424 & 3042 & 2946,2889 & 1612 & 1481 & 1255 \\
$\mathbf{H}_{2} \mathbf{L}^{2}$ & 3427 & 3045 & 2937,2883 & 1613 & 1480 & 1264 \\
$\mathbf{H}_{2} \mathbf{L}^{3}$ & 3441 & 3057 & 2941,2880 & 1611 & 1481 & 1261 \\
$\mathbf{H}_{2} \mathbf{L}^{\mathbf{4}}$ & 3433 & 3053 & 2941,2882 & 1614 & 1479 & 1265 \\
\hline
\end{tabular}




\begin{tabular}{|c|c|c|}
\hline \multicolumn{3}{|c|}{$\begin{array}{c}\text { TABLE-3 } \\
\text { THE UV-VISIBLE SPECTRA AND }{ }^{1} H \text { NMR DATA FOR THE SALAMO-TYPE BISOXIME COMPOUNDS } \mathbf{H}_{2} \mathbf{L}^{1}-\mathbf{H}_{2} \mathbf{L}^{4}\end{array}$} \\
\hline Compound & $\pi-\pi^{*}(\mathrm{~nm})$ & ${ }^{1} \mathrm{H}$ NMR $\left(400 \mathrm{MHz}\right.$, DMSO- $\left.d_{6}, \delta / \mathrm{ppm}\right)$ \\
\hline $\mathbf{H}_{2} \mathbf{L}^{1}$ & 270,324 & $\begin{array}{l}2.14\left(\mathrm{t}, J=6.0 \mathrm{~Hz}, 2 \mathrm{H}, \mathrm{CH}_{2}\right), 4.31\left(\mathrm{t}, J=6.0 \mathrm{~Hz}, 4 \mathrm{H}, \mathrm{CH}_{2}-\mathrm{O}\right), 6.85(\mathrm{~d}, J=8.0 \mathrm{~Hz}, 2 \mathrm{H}, \mathrm{PhH}), 7.25(\mathrm{~s}, 2 \mathrm{H}, \mathrm{PhH}), \\
7.33(\mathrm{~d}, J=8.0 \mathrm{~Hz}, 2 \mathrm{H}, \mathrm{PhH}), 8.09(\mathrm{~s}, 2 \mathrm{H}, \mathrm{N}=\mathrm{CH}), 9.80(\mathrm{~s}, 2 \mathrm{H}, \mathrm{OH})\end{array}$ \\
\hline $\mathbf{H}_{2} \mathbf{L}^{2}$ & 269,323 & $\begin{array}{l}2.04\left(\mathrm{t}, J=4.0 \mathrm{~Hz}, 4 \mathrm{H}, \mathrm{CH}_{2}\right), 4.23\left(\mathrm{t}, J=4.0 \mathrm{~Hz}, 4 \mathrm{H}, \mathrm{CH}_{2}-\mathrm{O}\right), 6.85(\mathrm{~d}, J=4.0 \mathrm{~Hz}, 2 \mathrm{H}, \mathrm{PhH}), 7.24(\mathrm{~s}, 2 \mathrm{H}, \mathrm{PhH}), \\
7.34(\mathrm{~d}, J=4.0 \mathrm{~Hz}, 2 \mathrm{H}, \mathrm{PhH}), 8.08(\mathrm{~s}, 2 \mathrm{H}, \mathrm{N}=\mathrm{CH}), 9.89(\mathrm{~s}, 2 \mathrm{H}, \mathrm{OH})\end{array}$ \\
\hline $\mathbf{H}_{2} \mathbf{L}^{3}$ & 277,315 & $\begin{array}{l}2.34\left(\mathrm{~s}, 2 \mathrm{H}, \mathrm{CH}_{2}\right), 2.37\left(\mathrm{~d}, J=8.7 \mathrm{~Hz}, 4 \mathrm{H}, \mathrm{CH}_{2}\right), 4.46\left(\mathrm{~s}, 4 \mathrm{H}, \mathrm{CH}_{2}-\mathrm{O}\right), 7.40(\mathrm{~d}, J=2.0 \mathrm{~Hz}, 2 \mathrm{H}, \mathrm{PhH}), 7.55(\mathrm{~d}, J= \\
2.0 \mathrm{~Hz}, 2 \mathrm{H}, \mathrm{PhH}), 7.72(\mathrm{~d}, J=2.2 \mathrm{~Hz}, 2 \mathrm{H}), 8.25(\mathrm{~s}, 2 \mathrm{H}, \mathrm{N}=\mathrm{CH}), 10.14(\mathrm{~s}, 2 \mathrm{H}, \mathrm{OH})\end{array}$ \\
\hline $\mathbf{H}_{2} \mathbf{L}^{4}$ & 276,322 & $\begin{array}{l}2.33\left(\mathrm{~s}, 4 \mathrm{H}, \mathrm{CH}_{2}\right), 2.36\left(\mathrm{~d}, J=8.0 \mathrm{~Hz}, 4 \mathrm{H}, \mathrm{CH}_{2}\right), 4.45\left(\mathrm{~s}, 4 \mathrm{H}, \mathrm{CH}_{2}-\mathrm{O}\right), 7.41(\mathrm{~d}, J=2.0 \mathrm{~Hz}, 2 \mathrm{H}, \mathrm{PhH}), 7.55(\mathrm{~d}, J= \\
2.0 \mathrm{~Hz}, 2 \mathrm{H}, \mathrm{PhH}), 7.71(\mathrm{~d}, J=2.2 \mathrm{~Hz}, 2 \mathrm{H}), 8.25(\mathrm{~s}, 2 \mathrm{H}, \mathrm{N}=\mathrm{CH}), 10.05(\mathrm{~s}, 2 \mathrm{H}, \mathrm{OH})\end{array}$ \\
\hline
\end{tabular}

\section{REFERENCES}

1. T.K. Saha, V. Ramkumar and D. Chakraborty, Inorg. Chem., 50, 2720 (2011).

2. R.M. Haak, A. Decortes, E.C. Escudero-Adán, M.M. Belmonte, E. Martin, J. Benet-Buchholz and A.W. Kleij, Inorg. Chem., 50, 7934 (2011).

3. C. Meermann, K.W. Törnroos and R. Anwander, Inorg. Chem., 48, 2561 (2009).

4. P.A. Vigato and S. Tamburini, Coord. Chem. Rev., 252, 1871 (2008).

5. Y. Sui, D.P. Li, C.H. Li, X.H. Zhou, T. Wu and X.Z. You, Inorg. Chem., 49, 1286 (2010).

6. S. Akine, S. Hotate and T. Nabeshima, J. Am. Chem. Soc., 133, 13868 (2011).

7. S. Akine, W.K. Dong and T. Nabeshima, Inorg. Chem., 45, 4677 (2006)

8. S. Akine, T. Tadokoro and T. Nabeshima, Inorg. Chem., 51, 11478 (2012).

9. W.K. Dong, X.N. He, H.B. Yan, Z.W. Lv, X. Chen, C.Y. Zhao and X.L. Tang, Polyhedron, 28, 1419 (2009).

10. (a) W.K. Dong, Y.X. Sun, C.Y. Zhao, X.Y. Dong and L. Xu, Polyhedron, 29, 2087 (2010); (b) S. Akine, T. Taniguchi, W. Dong, S. Masubuchi and T. Nabeshima, J. Org. Chem., 70, 1704 (2005); (c) W.K. Dong, C.Y. Zhao, Y.X. Sun, X.L. Tang and X.N. He, Inorg. Chem. Commun., 12, 234 (2009); (d) W.K. Dong, L. Wang, Y.X. Sun, J.F. Tong and J.C. Wu, Chinese J. Inorg. Chem., 27, 372 (2011); (e) W.K. Dong and Y.J. Ding, Cryst. Res. Technol., 43, 321 (2008); (f) W.K. Dong, Y.X. Sun, S.J. Xing, Y. Wang and X.H. Gao, Z. Naturforsch., 67, 197 (2012); (g) W.K. Dong, S.J. Xing, Y.X. Sun, L. Zhao, L.Q. Chai and X.H. Gao, J. Coord. Chem., 65, 1212 (2012); (h) W.K. Dong, Y.X. Sun, G.H. Liu, L. Li, X.Y. Dong and X.H. Gao, Z. Anorg. Allg. Chem., 638, 1370 (2012); (i) W.K. Dong, Y.X. Sun, X.N. He, J.F. Tong and J.C. Wu, Spectrochim. Acta A, 76, 476 (2010).

11. W.K. Dong, Y.X. Sun, Y.P. Zhang, L. Li, X.N. He and X.L. Tang, Inorg. Chim. Acta, 362, 117 (2009).

12. J.A. Faniran, K.S. Patel and J.C. Bailar Jr., J. Inorg. Nucl. Chem., 36, 1547 (1974).

13. T. Ghosh, B. Mondal, T. Ghosh, M. Sutradhar, G. Mukherjee and M. Drew, Inorg. Chim. Acta, 360, 1753 (2007).

14. H.E. Smith, Chem. Rev., 83, 359 (1983).

15. S. Akine, T. Taniguchi and T. Nabeshima, Chem. Lett., 30, 682 (2001). 